\title{
Number of Days from Date of Initial Cancer Diagnosis to Date of Additional Surgery for New Tumor Event
}

National Cancer Institute

\section{Source}

National Cancer Institute. Number of Days from Date of Initial Cancer Diagnosis to Date

of Additional Surgery for New Tumor Event. NCI Thesaurus. Code C156860.

The number of days from the date of the initial cancer diagnosis to the date of additional surgery for the new tumor event. 